\title{
ATHEROSCLEROSIS IS ASSOCIATED WITH NEUTROPHIL LYMPHOCYTE RATIO AS AN INFLAMMATORY MARKER IN TYPE 2 DIABETES MELLITUS PATIENTS WITH CORONARY ARTERY DISEASE
}

\author{
BHUIYAN MMA ${ }^{1}$, SULTANA T ${ }^{2}$, ISLAM MS ${ }^{3}$, BORUA D ${ }^{4}$, AHMED M $^{5}, \mathrm{KHAN} \mathrm{SH}^{6}$, PAUL D ${ }^{7}$, \\ RAHMAN $Q^{8}$, PANDIT $\mathrm{H}^{9}$, AHMED ANN ${ }^{10}$
}

\begin{abstract}
Background: Increased neutrophil lymphocyte ratio is associated with major adverse outcomes of cardiac events in type 2 diabetes mellitus (DM) patients.

Objective: To assess the NLR as an inflammatory marker in atherosclerosis in type 2 DM patients with coronary artery disease (CAD).

Methods: This case control study was conducted in the Department of Clinical Pathology in collaboration with Department of Cardiology, Bangabandhu Sheikh Mujib Medical University (BSMMU), Dhaka, from March 2014 to February 2015. Total 134 patients were enrolled in this study who were waiting for coronary angiography in the Department of Cardiology, BSMMU; 84 cases were considered as Group I (DM with CAD) and 50 controls were Group II (DM without $C A D)$. A $2 \mathrm{ml}$ of blood was collected in EDTA tube from the patients prior to coronary angiogram for complete blood count (CBC) were measured by haematology autoanalyzer, rechecked manually and NLR was calculated in the Department of Clinical Pathology, BSMMU. Coronary artery disease with 50\% coronary artery stenosis and more critical lesion that were diagnosed by coronary angiography were included in this study as cases. Coronary artery disease with less than 50\% coronary artery stenosis that was diagnosed by coronary angiography was included in this study as control.
\end{abstract}

Results: NLR was higher in CAD positive group compared to group without CAD negative in type 2 DM patients $(2.76( \pm 0.74)$ vs. $1.56( \pm 0.15), p<0.001)$.

Conclusion: With the help of neutrophil lymphocyte ratio we can take preventive measure and precaution to reduce the progression of atherosclerosis in type 2 diabetic patients with coronary artery disease.

Key words: Nutrophil lymphocyte ratio, Diabetes mellitus, Coronary artery disease.

J Dhaka Med Coll. 2015; 24(1) : 24-29.

1. Dr. Mohammad Monzurul Alam Bhuiyan, Clinical Pathologist, Department of Clinical Pathology, Dhaka Medical College Hospital, Dhaka.

2. Dr. Tuhin Sultana, Associate Professor, Department of Clinical Pathology, Bangabandhu Sheikh Mujib Medical University (BSMMU), Dhaka.

3. Dr. Md. Saiful Islam, Assistant Professor, Department of Clinical Pathology, Bangabandhu Sheikh Mujib Medical University (BSMMU), Dhaka.

4. Dr. Dhiman Borua, Medical Officer, Chittagong General Hospital, Chittagong.

5. Dr. Mostaque Ahmed, Emergency Medical Officer, Department of Transfusion Medicine, National Institute of Cardiovascular Diseases (NICVD), Dhaka.

6. Dr. Sarwar Hossain Khan, Indoor Medical Officer, Department of Urology, Dhaka Medical College Hospital, Dhaka.

7. Dr. Debatosh Paul, Associate Professor, Department of Clinical Pathology, Bangabandhu Sheikh Mujib Medical University (BSMMU), Dhaka.

8. Dr. Quddusur Rahman, Professor and Chairman, Department of Clinical Pathology, Bangabandhu Sheikh Mujib Medical University (BSMMU), Dhaka.

9. Dr. Harimohan Pandit, Junior Consultant Medicine, Mymensingh Medical College, Mymensingh

10. Dr. A.N. Nashimuddin Ahmed, Professor, Department of Clinical Pathology, Bangabandhu Sheikh Mujib Medical University (BSMMU), Dhaka.

Correspondence: Dr. Mohammad Monzurul Alam Bhuiyan, Clinical Pathologist, Department of Clinical Pathology, Dhaka Medical College Hospital, Dhaka. E-mail: drmonzucmc@gmail.com 


\section{Introduction}

Neutrophil lymphocyte ratio (NLR) is the sign of balance between neutrophil lymphocyte levels in the body and an indicator of systemic inflammation. ${ }^{1}$ NLR is a new indicator for cardiovascular risk and mortality and by which we can predict the risk of coronary artery disease (CAD) in type $2 \mathrm{DM}$ patients. ${ }^{2}$ Increased NLR is associated with major adverse cardiac events in type 2 diabetes mellitus patients. ${ }^{3,4}$ The relationship between various inflammatory markers and CAD has been established. ${ }^{5}$ Among these markers, the levels of white blood cell (WBC) subtypes confirmed inflammatory markers that play a crucial role in the pathogenesis of atherogenesis and atherothrombosis, have received significant attention. ${ }^{6}$ It has been established that the WBC count and levels of WBC subtypes not only play an important role in the development of $\mathrm{CAD}$, but can also be used to predict the clinical outcomes of patients with CAD. ${ }^{7}$

Diabetes is a group of metabolic disorders characterized by hyperglycemia resulting from defects in insulin secretion, insulin action, or both. ${ }^{8}$ Type 2 DM is a chronic disease associated with many complications. There is two to four fold increased risk of cardiovascular disease in type $2 \mathrm{DM}$ patients. About $52 \%$ cause of death in type $2 \mathrm{DM}$ is cardiovascular disease. ${ }^{9}$ According to WHO report, Bangladesh had 3.2 million of diabetic subjects in 2000 and the number is expected to increase to a staggering 11.1 million by $2030 .^{10}$

The current consensus states that if the type 2 diabetes mellitus occurs earlier, it leads to coronary atherosclerosis in a majority of the patients. Several mechanisms are likely to contribute to the accelerated atherosclerosis and increased chronic heart disease (CHD) risk in patients with type 2 diabetes mellitus. Important factors of premature coronary atherosclerosis include dyslipidemia, hypertension, hypercoagulability, poor glycemic control, smoking, obesity and lack of physical activity. ${ }^{11}$ Most important factors are hyperglycemia affecting the vessel wall, diabetic dyslipidemia, hyperglycemia against dyslipidemia and chronic inflammation in the vessel wall. ${ }^{12}$ Coronary artery disease occurs when part of the smooth muscle, elastic lining inside a coronary artery develops atherosclerosis. Inflammation plays a major role in all stage of atherogenesis and participates in the local, myocardial and systemic complications of atherosclerosis. ${ }^{13}$ The early phase of atherosclerosis involves in the recruitment of inflammatory cells from the circulation to the arterial wall. Increased number of circulating neutrophils is a well known risk indicator of future cardiovascular disease. ${ }^{14}$

Recently, the differential leukocyte count and elevated NLR has been the subject of interest in predicting the risk for future cardiovascular events. An elevated NLR independently indicates an increased long term risk of mortality in patients with stable CAD. ${ }^{15,16}$

In this study, it was aimed to investigate relationship between atherosclerosis and NLR as an inflammatory marker in type $2 \mathrm{DM}$ patients and to establish NLR as a useful predicator of adverse outcomes of CAD in type 2 DM patients.

\section{Methods}

This case control study was conducted at the Department of Clinical Pathology in collaboration with the Department of Cardiology, Bangabandhu Sheikh Mujib Medical University (BSMMU), Dhaka, from March 2014 to February 2015. 134 type 2 DM patients were enrolled in this study; 84 cases were considered as Group I (DM with CAD) and 50 controls were Group II (DM without CAD). Type $2 \mathrm{DM}$ patients with coronary artery disease who have e" 50\% stenosis, adults (18 years and above) patients, patients of both sexes were included in this study. Recurrent myocardial infarction, patients with congenital cardiac disease as shunt or vascular anomalies, pulmonary hypertension (both primary or secondary), acute or chronic infectious diseases, uncontrolled hypertension, known case of patients with cerebrovascular diseases, patients with documented malignancy, hematological disorders, patients with hepatic and renal impairment were excluded from the study. In this study patient's complete blood counts were measured by haematology 
autoanalyzer (SYSMEX 4000i), rechecked manually and NLR was calculated in the Department of Clinical Pathology, BSMMU.

After selection, all the patients were thoroughly informed about the aims, objectives and procedure of the study and were encouraged for their voluntary participation. Then an informed written consent was taken from each subject. Detail personal, medical, occupational, educational and smoking histories were recorded in a preformed data schedule and thorough physical examinations were done and documented. Tests done in Dept. of Clinical Pathology: $\mathrm{CBC}$ with $\mathrm{PBF}$ including differential count of WBC, erythrocyte sedimentation rate (ESR) and neutrophil lymphocyte ratio (NLR). Reports collected from patient's file were: plasma glucose- fasting (FPG), plasma glucose 2 hours after $75 \mathrm{~g}$ glucose (PPBG), glycated haemoglobin (HbA1c), serum lipid profile, serum creatinine, alanine aminotranferase (ALT).

\section{Results}

The mean age of the DM with CAD (Group I) was $54.73 \pm 8.94$ years, the mean age of the DM without CAD (Group II) was $53.10 \pm 9.47$ years. It was observed that in Group I (DM with CAD) $75(89.28 \%)$ patients were male and $9(10.71 \%)$ patients were found female. In Group II (DM without CAD) 23 (46\%) patients were male and 27 (54\%) patients were female (Fig. 1). All the respondents were divided into three groups

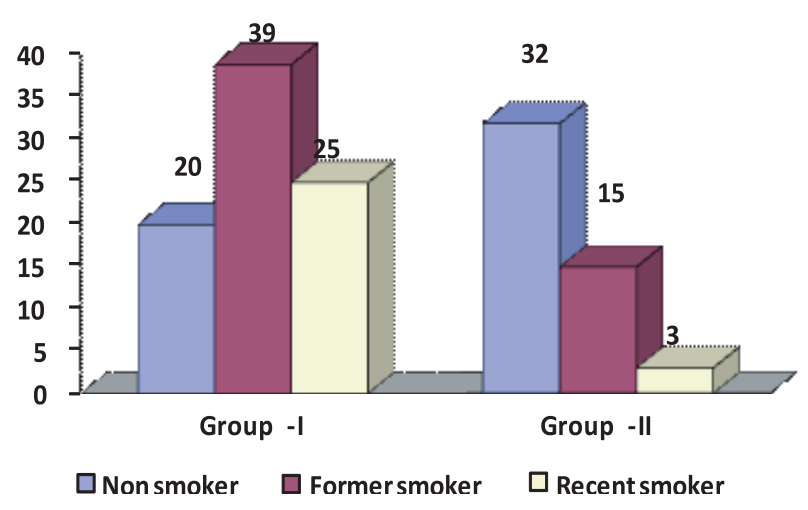

Fig. 1: Sex distribution of the study population ( $n=134)$.

${ }^{*}$ Chi-square test was done to measure level of significance $(P<0.001)$. according to their smoking habit, namely nonsmoker, former smoker and recent smoker. In this study, it was observed that majority 64 (75.0\%) patients in Group I were smoker (39 patients were former and 25 patients were recent smoker), whereas only 18 (36\%) patients were smoker in Group-II (15 patients were former smoker and 3 patients were recent smoker). This association was highly significant $(p<0.001)$ (Fig. 2).

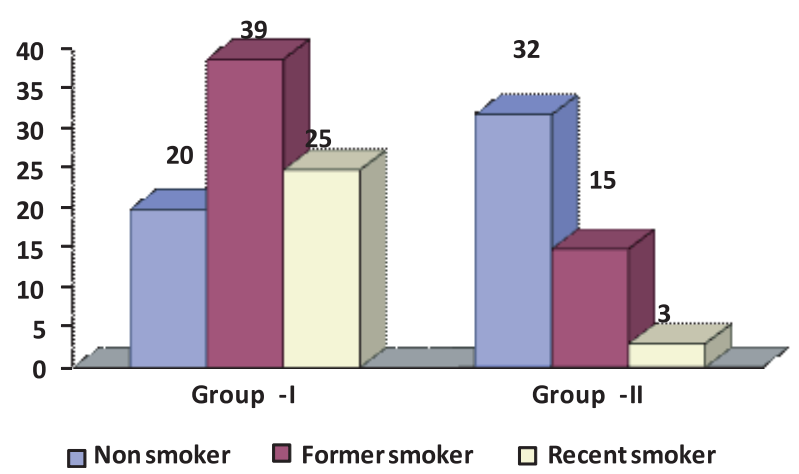

Fig. 2: Smoking status of the study population $(n=134)$.

${ }^{*}$ Chi-square test was done to measure level of significance $(p<0.001)$.

Mean total count of WBC were found $9.90 \pm(1.91)$ x 109/L in Group I and $8.66 \pm(1.37) \times 109 / \mathrm{L}$ in Group II. This association is highly significant ( $\mathrm{p}<0.001)$. On the other hand, mean ESR were $31.07 \pm(18.25)$ in Group I, whereas it was 11.76 \pm (6.20) in group II which was statistically highly significant ( $\mathrm{p}<0.001)$ (Table-I). HbA1c (\%) was $7.40 \pm 1.04$ (Mean $\pm \mathrm{SD}$ ) in Group I whereas it was $6.13 \pm 0.65$ (Mean \pm SD) in Group II. This association is statistically highly significant $(\mathrm{p}<0.001)$ (Table-II). Table-III shows mean NLR with sex, NLR in male were $2.44( \pm 0.82)$ and female $1.92( \pm 0.76)$, which was statistically significant $(\mathrm{p}<0.008)$. Table-IV shows mean NLR were $2.76( \pm 0.74)$ in Group-I patients and $1.56( \pm 0.15)$ in Group-II patients which was statistically highly significant ( $p<0.001)$. NLR was significantly increased in Group-I and normal or not significantly increase in GroupII. This result reflects that by NLR we can predict the risk of coronary artery disease in type 2 DM patients. In Group-I NLR was more than the calculated cut off value. The range of NLR in Group-I was 2.0-7.0 and the range of NLR in Group-II was 1.23-1.74. 
Table-I

Association between Group-I and Group-II with mean total WBC count and ESR ( $n=134)$

\begin{tabular}{|c|c|c|c|}
\hline & Group-I & Group-II & $\mathrm{P}$ \\
\hline & Mean \pm SD & Mean \pm SD & value* \\
\hline $\mathrm{TC}$ of $\mathrm{WBC}\left(10^{9} / \mathrm{L}\right)$ & $9.90 \pm(1.91)$ & $8.66 \pm(1.37)$ & \\
\hline Range (min-max) & $5-13.50$ & $6-13.0$ & $<0.001$ \\
\hline $\mathrm{ESR}\left(\mathrm{mm} / 1^{\text {st }}\right.$ hour $)$ & $31.07 \pm(18.25)$ & $11.76 \pm(6.20)$ & $<0.001$ \\
\hline Range (min-max) & $5-120$ & $3-28.0$ & \\
\hline
\end{tabular}

* Unpaired sample t test was done to measure level of significance.

Table-II

Mean difference between Group-I (DM with CAD) and Group-II (DM without CAD) with HbA 1c (\%) $(n=134)$

\begin{tabular}{cccc}
\hline & $\begin{array}{c}\text { Group-I } \\
\text { Mean } \pm \mathrm{SD}(\mathrm{n}=84)\end{array}$ & $\begin{array}{c}\text { Group-II } \\
\text { Mean } \pm \mathrm{SD}(\mathrm{n}=50)\end{array}$ & $\begin{array}{c}P \\
\text { value }^{*}\end{array}$ \\
\hline HbA1c $(\%)$ & $7.40 \pm(1.04)$ & $6.13 \pm(0.65)$ & $<0.001$ \\
\hline
\end{tabular}

* Unpaired sample t test was done to measure level of significance.

Table III

Distribution of mean NLR with sex $(n=134)$

\begin{tabular}{lccc}
\hline & \multicolumn{2}{c}{ Sex } & $P$ - \\
& Mean \pm SD & Mean \pm SD & value* $^{*}$ \\
\hline NLR & $2.44( \pm 0.82)$ & $1.92( \pm 0.76)$ & 0.008 \\
Range & $1.23-7.0$ & $1.25-5.0$ & \\
(min-max) & & \\
\hline
\end{tabular}

* Unpaired sample t test was done to measure level of significance.

Table IV

Mean NLR difference between Group-I and Group-II

\begin{tabular}{lccc}
\hline & $\begin{array}{c}\text { Group-I } \\
\text { Mean } \pm \text { SD }\end{array}$ & $\begin{array}{c}\text { Group-II } \\
\text { Mean } \pm \text { SD }\end{array}$ & $\begin{array}{c}P \\
\text { value* }\end{array}$ \\
\hline NLR & $2.76( \pm 0.74)$ & $1.56( \pm 0.15)$ & $<0.001$ \\
$\begin{array}{l}\text { Ratio) } \\
\text { Range }\end{array}$ & $2.0-7.0$ & $1.23-1.74$ & \\
(min-max) & & \\
\hline
\end{tabular}

* Unpaired sample t test was done to measure level of significance. Cut off value of NLR was 1.74 .

\section{Discussion:}

Type $2 \mathrm{DM}$ is a chronic disease associated with many complications. ${ }^{17}$ Patients with type $2 \mathrm{DM}$ have an increased incidence of atherosclerotic cardiovascular, peripheral arterial and cerebrovascular disease. ${ }^{18}$ Cardiovascular disease accounts for up to $80 \%$ of deaths in individuals with type 2 DM. $^{19}$ Type 2 DM patients have a threefold higher risk than nondiabetic individuals of developing atherosclerosis and its clinical complications, such as stroke, myocardial infarction (MI) and peripheral vascular disease. ${ }^{12,20}$ Despite improvement in primary prevention and treatment, CAD remains the chief cause of death in most developed countries. ${ }^{21}$ The incidence is much greater in developing countries. ${ }^{22}$

CAD occurs at any adult age, but it is the disease of middle and old age. In our study, the mean age of the patients in Group I (DM with CAD) was $54.73( \pm 8.94)$ years as compared to $56.59 \pm 13.63$ years and $58.01 \pm 12.9$ years, studies done by Assiri et al. (2012) and Al-Saif et al. (2011). It was $52.0 \pm 8.6$ years in a study reported by Siddique et al. (2010) and 56.6 years by Ullah M et al., (2011) in Bangladesh. ${ }^{21,23-25}$ 
Mean total count of WBC was found $9.90 \pm(1.91)$ x $10^{9} / \mathrm{L}$ in Group I and $8.66 \pm(1.37) \times 10^{9} / \mathrm{L}$ in Group II. This association is highly significant $(p<0.001)$. On the other hand, mean ESR was $31.07 \pm 18.25 \mathrm{~mm}$ in $1^{\text {st }}$ hour in Group I whereas it was $11.76 \pm 6.20 \mathrm{~mm}$ in $1^{\text {st }}$ hour in Group II which was statistically highly significant $(p$ $<0.001$ ). Our findings are similar to other study conducted by Selcuk et al. (2011). ${ }^{26}$ They found significantly higher WBC count $(8.2 \mathrm{vs} 7.4, \mathrm{p}$ value 0.001$)$ and ESR (25.5vs12.02, p value $<0.001)$ in CAD group. In another study conducted by Sonmez et al. (2013), they also found higher WBC count in DM with CAD group (7.75 vs 7.01 , $\mathrm{p}$ value 0.01$)^{2}$

Glycemic control, measured here by HbA1c, was associated with CAD among type $2 \mathrm{DM}$ patients. In our study, it was observed that mean $\mathrm{HbA} 1 \mathrm{c}$ $\%$ was significantly higher in the DM with CAD group ( $7.40 \pm 1.04$ vs $6.13 \pm 0.65)(p<0.001)$. Our results reinforce the concept that glycemic control plays an important role in the presence of CAD, at least in this group of type $2 \mathrm{DM}$ patients with high cardiovascular risk. ${ }^{27}$ Even in non-diabetic individuals $\mathrm{HbA} 1 \mathrm{c}$ can be associated with CAD and its severity. ${ }^{28}$

In this study, we found a relation of NLR with the presence of coronary artery disease. There is no doubt in cardiovascular medical science that atherosclerosis is a chronic inflammatory disease. ${ }^{13,29}$ In our study, mean NLR in Group I was $2.76( \pm 0.74)$, whereas it was $1.56( \pm 0.15)$ in Group II. There was statistically significant association between two groups in this regards ( $p<0.001$ ). Our findings are similar to a study conducted by Sahin et al. (2013). ${ }^{1}$ They also found higher mean NLR in patients with CAD group $(1.98 \pm 0.85$ vs $2.69 \pm 1.74)(p<0.001)$. Sonmez et al. (2013) also found higher mean NLR in patients with coronary artery disease (2.3 vs 1.6$)(p<0.001){ }^{2}$

Blood NLR is a new indicator of the overall inflammatory status of the body. It is a simple, inexpensive and useful marker of subclinical inflammation. NLR can be a useful tool to detect and measure the future prognosis and adverse outcomes of atherosclerosis in diabetic patients with CAD. In this study, we found a relationship between NLR and atherosclerosis in CAD proven with coronary angiography and NLR is a useful predicator of atherosclerosis in type 2 DM patients with CAD.

\section{Limitations}

The main limitation of our study was the small sample size and this was a non-randomized single center study. We did not compare the prognostic value of NLR with other inflammatory markers such as: CRP, interleukin-1 (IL-1), interleukin-6 (IL-6) and TNF- \pm etc.

\section{Conclusion}

By the assesment of NLR we can take preventive measure and precaution to reduce the progression of atherosclerosis in type 2 diabetic patients with CAD. NLR is a simple, cost effective, readily available test and could be calculated easily to predict the atherosclerosis and can take extra measure and preventive intervention to prevent the atherosclerosis in type $2 \mathrm{DM}$ patients with CAD.

\section{Acknowledgements}

The authors of this study are thankful to the authority of the Department of Cardiology, BSMMU and the Department of Clinical Pathology, BSMMU, for their nice cooperation during sample collection, laboratory procedure and also thankful to the study subjects for their active and enthusiastic participation.

\section{References}

1. Sahin S, Sarikaya S, Akyol L, Altunkas F, Karaman K. Evaluation of neutrophil to lymphocyte ratio as an indicator of presence of coronary artery disease in diabetic patients, National $\mathrm{J}$ Med Res 2013; 3(4), 300.

2. Sönmez O, Erta_ g, Bacaks1z A, Tasal A, Erdoan E, Asolu E, Uyarel H, Göktekin O. Relation of neutrophil to lymphocyte ratio with the presence and complexity of coronary artery disease: an observational study. Anadolu Kardiyol Derg 2013; 13; 662-7.

3. Azab B, Chainani V, Shah N, McGinn JT. Neutrophil lymphocyte ratio as a predictor of major adverse cardiac events among diabetic population: a 4 year follow up study. Angiology 2013; 64: 45665.

4. Lee GK, Lee LC, Chong E, et al. The Long-Term Predictive Value of the Neutrophil-to Lymphocyte Ratio in Type 2 Diabetic Patients Presenting with Acute Myocardial Infarction. QJM 2012; 105(11): 1075-82. 
5. Ate_ AH, Canpolat U, Yorgun $\mathrm{H}$, et al. Total white blood cell count is associated with the presence, severity and extent of coronary atherosclerosis detected by dual source multislice computed tomographic coronary angiography. Cardiol J 2011; 18: 371-7.

6. Horne BD, Anderson JL, John JM, et al. Intermountain Heart Collaborative Study Group. Which white blood cell subtypes predict increased cardiovascular risk? J Am Coll Cardiol 2005; 45: 1638-43.

7. Madjid M, Awan I, Willerson JT, Casscells SW. Leukocyte count and coronary heart disease: implications for risk assessment. J Am Coll Cardiol 2004; 44: 1945-56.

8. American Diabetic Association. Standards of medical care in diabetes. Diabetic Care 2013; 36 (Suppl 1): S 11-66.

9. Morrish NJ, Wang SL, Stevens LK, Fuller JH, Keen $\mathrm{H}$. Mortality and causes of death in the WHO multinational study of vascular disease in diabetes. Diabetologia 2001; 44(Suppl. 2): 14-21.

10. Akhter A, Fatema K, Afroz A, Bhowmik B, Ali L, Hussain A. prevalence of diabetes mellitus and its associated risk indicators in a rural Bangladeshi population. Open Diabetes Journal 2011; 4: 6-13.

11. Folsom AR, Aleksic N, Catellier D, Juneja HE, Wu KK. C-Reactive Protein and Incident Coronary Heart Disease in the Atherosclerosis Risk in Communities (Aric) Study, Am Heart J 2001; 144(2): 233-8.

12. Huxley R, Barzi F, Woodward M. Excess risk of fatal coronary heart disease associated with diabetes in men and women: meta-analysis of 37 prospective cohort studies. BMJ 2006; 332: 73-8.

13. Libby P, Ridker PM, Maseri A. Inflammation and atherosclerosis. Circulation 2002; 105(9): 1135-43.

14. Sarndahl E, Bergstrom I, Brodin VP, et al. Neutrophil activation status in stable coronary artery disease. PLoS One 2007; 2: e1056.

15. Papa A, Emdin M, Passino C, et al. Predictivevalue of elevated neutrophil-lymphocyte ratio on cardiac mortality in patients with stable coronary artery disease. Clin Chim Acta 2008; 395: 27-31.

16. Nunez J, Nunez E, Bodi V, et al. Usefulness of the neutrophil to lymphocyte ratio in predicting long-term mortality in ST segment elevation myocardial infarction. Am J Cardiol 2008; 101: 747-52.

17. Ramachandran A, Snehalatha C, Viswanathan V. Burden of type 2 Diabetes and its complications the Indian scenario. Curr Sci 2002; 83: 1471-6.
18. Nishimura R, Nakagami T, Sone H, Ohashi $\mathrm{Y}$, Tajima N. Relationship between Hemoglobin A1c and Cardiovascular Disease in Mild to Moderate Hypercholesterolemic Japanese Individuals: Sub analysis of a Large-Scale Randomized Controlled Trial. Cardiovasc Diabetol 2011; 10: 58.

19. Haffner SM, Lehto S, Rönnemaa T, Pyörälä K, Laakso M. Mortality from coronary heart disease in subjects with type 2 diabetes and in nondiabetic subjects with and without prior myocardial infarction. N Engl J Med 1998; 339: 229-34.

20. Schaan BD, Reis AF. Cardiovascular disease and diabetes. Arq Bras Endocrinol Metabol 2007, 51: 151-2.

21. Assiri AS, Jamil AM, Mahfouz AA, Mahmoud ZS, Ghallab M. Diagnostic importance of platelet parameters in patients with acute coronary syndrome admitted to a tertiary care hospital in southwest region, Saudi Arabia. J Saudi Heart Assoc 2012; 24(1): 17-21.

22. Akanda MAK, Ali SY, Islam AEMM, et al. Demographic profile, clinical presentation \& angiographic findings in 637 patients with coronary heart disease. Faridpur Med Coll J 2011; 6(2); 82-5.

23. Al-Saif SM, Al-Habib KF, Ullah A, et al. Age and its relationship to acute coronary syndromes in the Saudi Project for Assessment of Coronary Events (SPACE) registry: The SPACE age study. J Saudi Heart Assoc 2012; 24: 9-16.

24. Siddique MA, PrakashShrestha M, Salman M, et al. Age-related differences of risk profile and angiographic findings in patients with coronary heart disease. BSMMU J 2010; 3(1): 13-7.

25. Ullah M, Sayami LA, Khan MR, et al. In hospital outcome of myocardial infarction in nondiabetic patients with high on admission blood glucose level. Cardiovascular J 2011; 3(2): 143-8.

26. Selcuk H, Dinc L, Selcuk MT, Maden O, Temizhan A. The relation between differential leukocyte count, neutrophil to lymphocyte ratio and the presence and severity of coronary artery disease. Open J Internal Med 2012; 2: 163-9.

27. Pistrosch F, Natali A, Hanefeld M. Is hyperglycemia a cardiovascular risk factor? Diabetes Care 2011; 34(Suppl 2): S128-31.

28. Ashraf H, Boroumand MA, Amirzadegan A, Talesh SA, Davoodi G. Hemoglobin A1C in non-diabetic patients: an independent predictor of coronary artery disease and its severity. Diabetes Res Clin Pract 2013; 102: 225-32.

29. Ross R. Atherosclerosis - an inflammatory disease. N Engl J Med 1999; 340(2).26-115: 